\title{
Simulation of the Electrochemical and Thermal Properties of Electric Vehicle Power Batteries
}

\author{
JING JING LI, MENG CHEN* \\ Northeast Forestry University, 26 Hexing Road Harbin, China
}

\begin{abstract}
The optimal energy and power performance of lithium ion batteries can be attained if a suitable thermal battery management system is used. Furthermore, to ensure the safe operation, a well functioning temperature control method, is needed. To achieve these goals, the simulation software COMSOL Multiphysics used to construct a three-dimensional electrochemical/thermal model of a monomer lithium ion battery. The simulation makes it possible to study the thermal characteristics at different ambient temperatures and different discharge rates. The obtained main outcomes are 1) The temperature of the lithium ion battery increases with increasing discharge ratio, and a sudden temperature increase is observed for higher discharge ratios, 2) For constant discharge rates, the temperature increase of the battery occurs mainly in the positive and negative electrode region, while lower temperatures are observed in the center and lower-edge region. A comparison between simulation and obtained date, indicates that the three-dimensional electrochemical/thermal model of the monomer lithium ion battery described the lithium ion battery well in terms of both heat generation and heat transfer.
\end{abstract}

Keywords: Lithium ion battery, Electrochemical/thermal model, Temperature distribution, heat generation

\section{Introduction}

Lithium batteries are possibly the best-suited energy storage media for electric vehicles. This is because of the high specific energy and power density, low self-discharge rate, and lack of memory effect [1]. These benefits have a lot to do with the battery structure and the materials used. At present, lithium ion batteries mainly consist of the anode and cathode materials, a diaphragm, and the electrolyte. The anode materials are generally metal oxides with a higher lithium content, such as $\mathrm{LiMn}_{2} \mathrm{O}_{4}, \mathrm{LiCoO}_{2}$, and $\mathrm{LiFePO}_{4}$. Commonly used anode materials are lithium embedded carbon compounds, graphite based materials, Sn oxides, Sn alloys, silicon alloys, and nano-materials (carbon nanotubes, nano-alloy materials). Thanks to the wide range of available electrode materials, lithium batteries can be produced with both a long service life and fairly high safety ratings.

However, there is still substantial room for improvement, especially for applications in electric vehicles, where safety, cost, and high/low-temperature performance are particularly important. To enable further improvements, it is important to better understand the thermal properties of lithium batteries during the charging and discharging processes.

Several one-dimensional electrochemical models were already used to numerically simulate and analyze the electrochemical and thermal characteristics of battery cells [2-3]. These models generally assume one-dimensional electrode, and a uniform potential at the current-collector plane. These assumptions, however, are generally only suitable to estimate averages for small lithium-ion batteries. For large batteries, the phenomenon of non-harmonious heat and current distribution is more obvious, and numerical simulation and solutions that use multi-dimensional models are regarded as best [4].

*email: meng.c163@gmail.com, chenmeng623@126.com 
Among multi-dimensional models, the following were extensively studied for automobile batteries: the single-particle model [5], the equivalent-circuit model [6,7] and the three-dimensional concentrated heat model [8-12]. The single particle model assumes that the concentration gradient in the electrolyte is uniform. The equivalent-circuit model uses a resistance network and voltage source to characterize the electrochemical impedance of a lithium ion battery.

The three-dimensional heat-collection model assumes that the layer structure of the battery is a uniform material with harmonious electrical and thermal characteristics, heat production, and temperature distribution. These models are relatively effective; however, they do not take into account details of the electrochemical process in the lithium ion battery. In addition, the heat generation in the battery is assumed uniform. To overcome the deficiencies of the above model, an electrochemical/thermal coupling model was proposed $[13,14]$. Using the porous electrode method and Pals and Newman's energy-conservation equation [15], the model simulated the internal electrochemical and heat generation process in a lithium battery. For example, $\mathrm{Xu}$ et al. developed a three-dimensional electrochemical/thermal model, which is suitable for $\mathrm{LiFePO}_{4} /$ graphite cells. It is based on the basic principles of the models above [16]. However, to the best of our knowledge, this model has never been used to study actual heat transfer and heat release in batteries.

In this paper, the mass-, charge-, and energy-conservation principle as well as electrochemical and kinetic coupling methods are used to develop a three-dimensional electrochemical/thermal model for a commercial 68 Ah lithium iron phosphate battery. By simulating the surface temperature distribution, electrolyte concentration, and current-density during discharge, the temperature variation within a lithium battery was studied for different ambient temperatures. Our work aims to be a solid starting point for the next generation of thermal management of lithium batteries. Both the complex electrochemical process, including the heat generation, of lithium ion batteries is studied in detail. The outcomes may help provide ideas for future research of the thermal characteristics of different electrode types of lithium batteries.

\section{Materials and methods}

The test consisted of a performance- and a heat-dissipation-measurment. Structurally, the test platform consisted of a lithium ion battery test-setup and a lithium ion battery ambient-temperature control- and monitoring-setup (Figure 1).

\subsection{Lithium ion battery test-setup}

The lithium ion battery test-setup (built by Changshatai measurement and control technology co., LTD) consists of hardware (Arbin battery-test system) and software (MITS Pro control system). The MITS Pro control-system can be used to select charge- and discharge-monitoring, for different constant-voltage-, constant-current-, and cycling-conditions.

\subsection{Ambient temperature control and monitoring system for lithium ion batteries}

The temperature-control system of a lithium ion battery (built by Shanghai Hetian scientific instrument co., LTD.) consists of a controllable high- and low-temperature incubator (external dimensions: $470 * 490 * 700 \mathrm{~mm}$, capacity: $50 \mathrm{~L}$ ), and a thermocouple sensor. The operating-temperature range of the temperature box was 5 to $65^{\circ} \mathrm{C}$, and the precision was $\pm 0.5^{\circ} \mathrm{C}$. During the test, it was used to simulate the actual working (ambient) temperature of a lithium ion battery. This ensured accurate temperature monitoring and good adiabatic performance. A suitable thermocouple sensor (Shanghai Chi control automation instrument co. LTD., measurement range: -200 to $3500^{\circ} \mathrm{C}$, measurement accuracy: $+/-0.50^{\circ} \mathrm{C}$ ) was used. Temperature monitoring was carried out in four areas of the single battery, and the four test points (t-type thermocouples) were: near the negative pole, near the positive pole, the battery surface center, and at the lower edge of the battery surface. These locations are referred to as T1, T2, T3, and T4, respectively - Figure 2. Table 1 shows the used technical parameters for a real battery used for the simulation. 


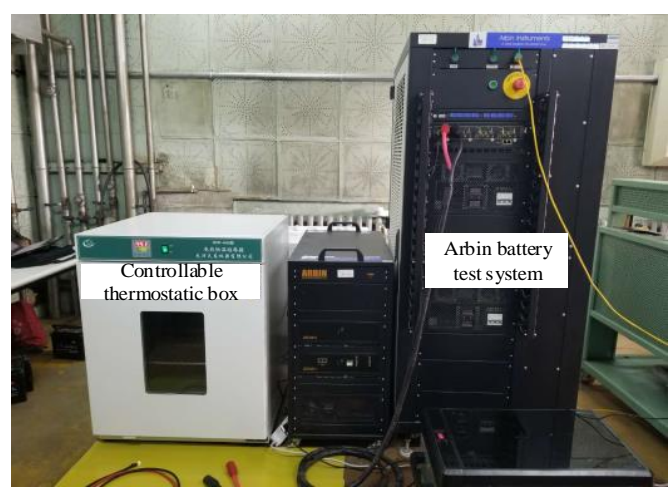

Figure 1. Lithium ion battery test-setup
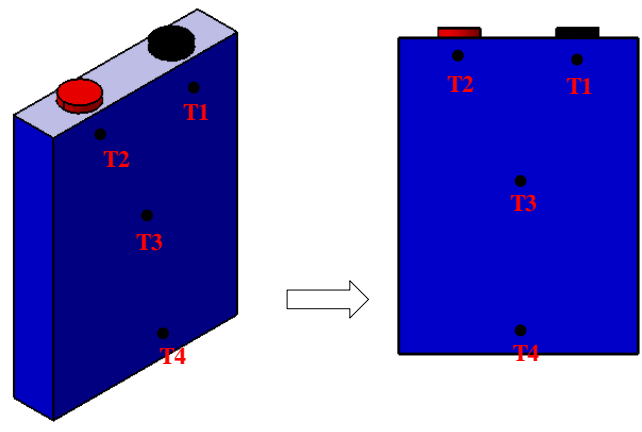

Figure 2. Thermocouple locations for the single lithium ion battery

Table 1. Used technical parameters of the real battery

\begin{tabular}{cc} 
technical parameter name & Values \\
nominal capacity/A.h & 68 \\
nominal voltage/V & 3.2 \\
charge cur-off voltage/V & 3.65 \\
discharge cur-off voltage/V & 2.5 \\
operating temperature/ $\mathrm{C}$ & $-20-55$ \\
max continuous discharge current/C & 3 \\
max continuous discharge current/C & 1 \\
size/mm & $29.3 \times 135.5 \times 185.3$ \\
\hline
\end{tabular}

\subsection{Development of the model}

To effectively calculate and analyze, the heat-generation characteristics of a prismatic lithium iron phosphate battery, an electrochemical/thermal model of the monomer lithium battery was created using the software COMSOL Multiphysics. The model was based on two-way coupling. In essence, both reversible heat and irreversible heat in the battery were calculated using the electrochemical model. The heat yield per unit volume was then plugged into the thermal model. As a result, the threedimensional model includes a heat source and temperature-related parameters (reversible entropy change $=\Delta S$, heat generation in the battery $=\dot{q}$ ). This means that the temperature distribution of the battery could be characterized together with the temperature behind the electric field in the threedimensional model. The temperature-related parameters (local charge-transfer current density $=J_{n}$, ion-current density in the electrolyte $=i_{l}$ ) in the electrochemical reaction changed with the changing temperature, which affected the heat production rate and temperature field distribution in the battery. Figure 3 shows the process of heat generation in the lithium battery. In addition, the relevant technical parameters of the model are listed in Tables 2 and 3. 


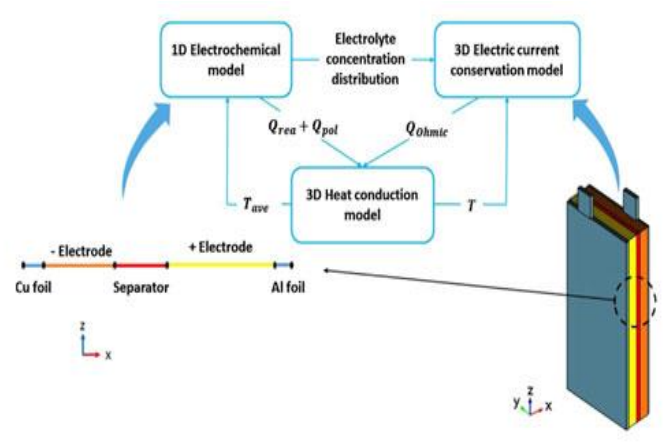

Figure 3. Schematic, illustrating the heat generation

Model in the prismatic lithium iron phosphate battery

Table 2. Parameters used in the electrochemical model

\begin{tabular}{cccc}
\hline parameter & cathode & diaphragm & anode \\
\hline particle radius of active substance $(\mathrm{m})$ & $8.091 \times 10^{-6}$ & - & 0.603 \\
volume fraction for solids & 0.647 & - & 0.336 \\
& & 0.269 & 0 \\
volume fraction of electrolyte $\left(\mathrm{LiPF}_{6}\right)$ & 0.269 & - & \\
initial electrolyte salt concentration \\
$\left(\mathrm{mol} / \mathrm{m}^{3}\right)$
\end{tabular}

Table 3. Parameters used in the 3D thermal model

\begin{tabular}{cccccc}
\hline parameter & $\begin{array}{c}\text { cathode current } \\
\text { collector }\end{array}$ & cathode & diaphragm & anode & anode current collector \\
& 385 & 1437.4 & 1978.16 & 1269.21 & 875 \\
hot melting $\left(\mathrm{J} /\left(\mathrm{kg}^{*} \mathrm{~K}\right)\right)$ & $5 \times 10^{-6}$ & $5.45 \times 10^{-5}$ & $1.6 \times 10^{-5}$ & $7.55 \times 10^{-5}$ & $8.5 \times 10^{-6}$ \\
Length $(\mathrm{m})$ & 8933 & 2250 & 1008.98 & 3600 & 2770 \\
Density $\left(\mathrm{kg} / \mathrm{m}^{3}\right)$ & 398 & 1.04 & 0.344 & 1.58 & 170 \\
heat conductivity coefficient & & & & \\
$\left(\mathrm{W} /\left(\mathrm{m}^{\cdot} \mathrm{K}\right)\right)$ & & &
\end{tabular}

\subsection{Electrochemical model for a prismatic lithium iron phosphate battery \\ 2.4.1.Electrochemical kinetic characterization in the model}

In an electrolyte, the current collector fluid is bounded by an ionic charge-balancing insulator. For a negative current collector, the electron current equilibrium potential is $0 \mathrm{~V}$, while the current density for a positive current collector is determined by the rate of discharge ratio (C). The internal boundary in front of the baffle is electrically insulated in the electron current of the adjacent layers. Using the Butler-Volmer equation, the local charge-transfer current density $\left(J_{n}\right)$ at the electrode is given as:

$$
J_{n}=J_{0}\left\{\exp \left(\frac{\alpha_{a} F}{R T} \cdot \eta\right)-\exp \left(\frac{-\alpha_{c} F}{R T} \cdot \eta\right)\right\}
$$

Here, $J_{0}$ is the exchange current density, $\mathrm{m} / \mathrm{A}^{2} ; \alpha_{a}$ and $\alpha_{c}$ are the anode transfer coefficient and cathode transfer coefficient, respectively, unit $1 ; \eta$ represents the over potential, $\mathrm{V} ; F$ is the Faraday constant, $96485 \mathrm{C} / \mathrm{mol} ; R$ is the gas constant, $8.314 \mathrm{~J}^{*} \mathrm{~mol}^{-1 *} \mathrm{~K}^{-1} . T$ is reaction temperature, $\mathrm{K}$. The exchange current density can be obtained as:

$$
J_{0}=F k_{0} C_{l}^{\alpha_{a}}\left(c_{s, \max }-c_{s, \text { surf }}\right)^{\alpha_{a}}\left(c_{s, \text { surf }}\right)^{\alpha_{c}}
$$

The over potential can be obtained using: 


$$
\eta=\phi_{s}-\phi_{l}-U_{e q}
$$

Here, $k_{0}$ is the reaction-rate constant $(\mathrm{mol} / \mathrm{s}) ; c_{l}$ is the electrolyte concentration, $\mathrm{mol} / \mathrm{m}^{3} ; \alpha_{a}$ is the current transfer coefficient for the anode; $\alpha_{c}$ is the cathode's current transfer coefficient; $c_{s, \max }$ is maximum concentration, $\mathrm{mol} / \mathrm{m}^{3} ; c_{s, s u r f}$ is the lithium ion concentration at the surface, $\mathrm{mol} / \mathrm{m}^{3} ; \phi_{s}$ and $\phi_{l}$ are the solid- and liquid - phase potentials (V), respectively; $U_{e q}$ is the open-circuit electrode voltage that depends on SOC and temperature.

\subsubsection{Charge conservation in the model}

The charge conservation at the anode and cathode can be described as:

$$
\begin{aligned}
& \nabla \cdot i_{s}+\nabla \cdot i_{l}=0 \\
& \nabla \cdot i_{s}=-S_{a} j_{n} \\
& \nabla \cdot i_{l}=S_{a} j_{n}
\end{aligned}
$$

where, $i_{s}$ and $i_{l}$ are the current density in the solid phase and ion current density in the electrolyte $\left(\mathrm{A} / \mathrm{m}^{2}\right), \nabla$ is the Laplace operator. $S_{a}$ is the specific surface area of the porous electrode, which is the ratio of the interface area to solid phase volume at the porous electrode $\left(\mathrm{m}^{-1}\right)$. Furthermore, $j_{n}$ is the local current density $\left(\mathrm{A} / \mathrm{m}^{2}\right)$.

For the solid phase, the charge balance equation for electron transport can be written as:

$$
i_{s}=-\sigma_{s}^{e f f} \nabla \phi_{s}
$$

where, $\sigma_{s}^{\text {eff }}$ represents the effective conductivity of the solid phase $(\mathrm{S} / \mathrm{m}) . \phi_{s}$ represents the solid phase potential $(\mathrm{V})$. To determine the effective conductivity of the solid phase, $\sigma_{s}^{\text {eff }}$ was obtained using:

$$
\sigma_{s}^{e f f}=\sigma_{s} \varepsilon_{s} \gamma
$$

where, $\sigma_{s}$ is the conductivity $(\mathrm{S} / \mathrm{m}), \varepsilon_{s}$ is the electrode volume fraction, $\gamma$ is the Bergman coefficient, which is 1.5 in this model. In the electrolyte phase, the charge balance equation for lithium ion transport can be obtained as:

$$
i_{l}=-\sigma_{l}^{e f f} \nabla \phi_{l}+\frac{2 R T \cdot \sigma_{l}^{e f f}}{F}\left(1+\frac{\partial \ln f \pm}{\partial \ln c_{l}}\right)\left(1-t_{+}\right) \nabla\left(\ln c_{l}\right)
$$

where, $\sigma_{l}^{\text {eff }}$ is the effective conductivity of the liquid phase $(\mathrm{S} / \mathrm{m}), f \pm$ is the average molar active coefficient, $t_{+}$is the concentration of the electrolyte in the liquid phase $\left(\mathrm{mol} / \mathrm{m}^{3}\right), R$ is the general gas constant, and $T$ is the electrolyte temperature (K).

\subsubsection{Characterization of mass conservation in the model}

The conservation of lithium mass in active material particles can be expressed as:

$$
\frac{\partial c_{s}}{\partial t}-\frac{1}{r^{2}} \frac{\partial}{\partial r}\left(r^{2} D_{s} \frac{\partial c_{s}}{\partial r}\right)=0
$$


where, $t$ is the time (s), $D_{s}$ is the diffusion coefficient for lithium in the solid phase, $c_{s}$ is the concentration of lithium in the active material particles $\left(\mathrm{mol} / \mathrm{m}^{3}\right)$, and $r$ is the particle radius $(\mathrm{m})$. The conservation of mass for lithium ions in the electrolyte can be expressed as:

$$
\varepsilon_{l} \frac{\partial c_{l}}{\partial t}+\nabla \cdot J_{l}=\frac{S_{a} J_{n}}{F}
$$

where, $\varepsilon_{l}$ is the volume fraction of the electrolyte phase, $J_{l}$ is the molar flux of lithium ion, which is expressed as follows:

$$
J_{l}=-D_{l}^{e f f} \nabla \cdot c_{l}+\frac{i_{l} t_{+}}{F}
$$

where, $D_{l}^{\text {eff }}$ is the effective diffusion coefficient for the lithium ion in the electrolyte. The electrochemical properties of the battery were studied using the local current obtained through the model. Both electrochemical reaction heat and polarization heat were obtained for the charging and discharging process.

\subsection{Thermal model construction for a prismatic lithium iron phosphate battery}

Heat is normally generated within the active material. The energy balance equation was used to develop a heat model to predict the temperature distribution inside the battery. The calculation using the energy-balance equation is generally affected by both the reversible heat and the irreversible heat of the electrochemical reaction. The ohmic heat part of the irreversible heat, however, is mainly considered in the three-dimensional thermal model. Therefore, it is very important to predict both the heat generation inside the battery and the consistency of the time-dependent temperature-distribution.

The heat, which is generated by reversible entropy change, can be obtained using the following equation:

$$
\Delta S=-\frac{\partial \Delta G}{\partial T}=-n F \frac{\partial V^{\circ}}{n T}
$$

where, $\Delta G$ represents the Gibbs free energy change, which can be written as:

$$
\Delta G=-n F \partial V^{\circ}
$$

Furthermore, the heat that is generated by the battery can be described as:

$$
\dot{q}=I\left(V^{\circ}-V\right)-I T \frac{\partial V^{\circ}}{\partial T}
$$

Therefore, its energy equation can take the following form [17,18]:

$$
\rho C_{p} \frac{\partial T}{\partial t}=k \nabla^{2} T+\dot{q}-h A\left(T-T_{a}\right)
$$

where, $\dot{q}$ is the heat flux $\left(\mathrm{W}^{*} \mathrm{~m}^{2}\right) ; V^{\circ}$ is the open circuit voltage, $(\mathrm{V}) ; V$ is the lithium ion battery voltage, $(\mathrm{V}) ; k$ is the thermal conductivity, $\left(\mathrm{W}^{*} \mathrm{~m}^{-1 *} \mathrm{k}^{-1}\right) ; T$ is the battery temperature, $(\mathrm{K}) ; \rho$ is the density $\left(\mathrm{kg}^{*} \mathrm{~m}^{-3}\right), C_{p}$ is the heat capacity of the battery $\left(\mathrm{J}^{*} \mathrm{~K}^{-1}\right), h$ is the heat transfer coefficient for the surface of the battery $\left(\mathrm{W}^{*} \mathrm{~m}^{-2} * \mathrm{~K}^{-1}\right), A$ is the surface area of the battery $\left(\mathrm{m}^{2}\right)$, and $T_{a}$ is the ambient temperature $(\mathrm{k})$. 


\subsection{Boundary and initial conditions of the model}

The continuity of ion current, electrolyte phase, and lithium ion flux of the heat flux is effectively ensured by applying insulation boundary conditions for the solid phase current at the electrode/separator interface. The respective equation can be formulated as follows:

$$
\begin{aligned}
& \left.n \cdot i_{s}\right|_{\text {sep }}=0,\left.n \cdot i_{l}\right|_{\text {elec }}=\left.n \cdot i_{l}\right|_{\text {sep }} \\
& \left.n \cdot J_{l}\right|_{\text {elec }}=\left.n \cdot J_{l}\right|_{\text {sep }},\left.n \cdot Q\right|_{\text {elec }}=\left.n \cdot Q\right|_{\text {sep }}
\end{aligned}
$$

At the electrode/collector interface, an insulator was used for the ion current and lithium ion flux in the electrolyte phase. Both current and heat flux were used continuously. The respective equation is:

$$
n \cdot i_{l}=0, n \cdot J_{l}=0,\left.n \cdot i_{s}\right|_{\text {elec }}=\left.n \cdot i_{s}\right|_{c c},\left.n \cdot Q\right|_{\text {elec }}=\left.n \cdot Q\right|_{c c}
$$

The battery current was used at the positive terminal, and the negative terminal was grounded to simulate the discharge process.

For the anode terminal we can write:

and for the cathode terminal:

$$
n \cdot i_{s}=i_{\text {batt }}
$$

$$
\phi_{s}=0
$$

When the battery was exposed to air, the heat was determined largely via natural convection. Because the battery surface temperature was almost the same as the surrounding ambient temperature, radiative heat transfer was neglected. The following boundary conditions were used for the heat transfer model:

$$
-n \cdot Q=h\left(T_{s}-T_{a}\right)
$$

where, $T_{s}$ and $T_{a}$ represent the battery's surface temperature and the ambient temperature respectively.

The initial conditions were:

$$
c_{s}=c_{s, 0}, c_{l}=c_{l, 0}, T=T_{a}
$$

\section{Results and discussions}

\subsection{Voltage validation}

In order to verify the accuracy of the model, the voltage change of lithium battery has been simulated and verified by experiments. Figure 4 shows the comparison between the simulation data and the experimental data. Here, $\mathrm{C}$ refers to the discharge rate of the battery when the nominal capacity of the battery is unity. It can be seen that the simulated data agree with the experimental results. This confirms the accuracy of the simulation model developed in this paper. 


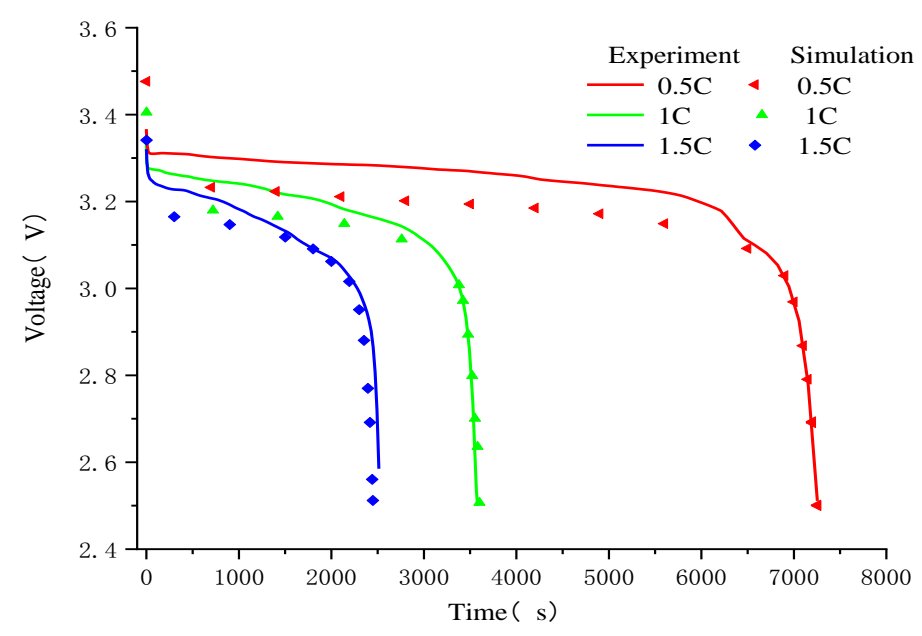

Figure 4. Simulated and tested voltage curves versus time for an ambient temperature of $25^{\circ} \mathrm{C}$

\subsection{Validation of the temperature increase}

A comparison between the simulation and experimental results for the lithium battery temperature at $25{ }^{\circ} \mathrm{C}$ (ambient temperature) and for different discharge rates $(0.5 \mathrm{C}, 1 \mathrm{C}$ and $1.5 \mathrm{C}$ ) is shown in Figure 5. Both data sets are similar, although the simulated temperatures were slightly below the measured results. In addition, the uniformity of the battery-surface temperature distribution has improved. The main reasons for the remaining few differences between simulation and experimental results may be:

a. The simulation parameters obtained from the literature likely differed from the actual battery parameters.

b. The assumption of a homogeneous electrochemical reaction on the surface of the active materials may be not completely realistic.

c. During discharge, the internal balance assumption of the battery could be inaccurate.

$\mathrm{d}$. The test was performed by reducing the load between the cable and the battery contact resistance to the maximum extent possible - but a small contact resistance remained. Some of the heat generated by the connection-plate transferred to the active material, which could have caused the temperature to increase, and led to a less homogeneous temperature distribution.

e. In the simulation, the battery was considered an ideal and uniform active material. However, due to the practical limitations during battery manufacturing and packaging, a uniform distribution of active material inside the battery is hard to achieve.

It can be concluded from Figure 5 that despite these deviations, the simulated data agreed well with the experiment, which confirms the accuracy of the electrochemical and thermal model for lithium batteries. 


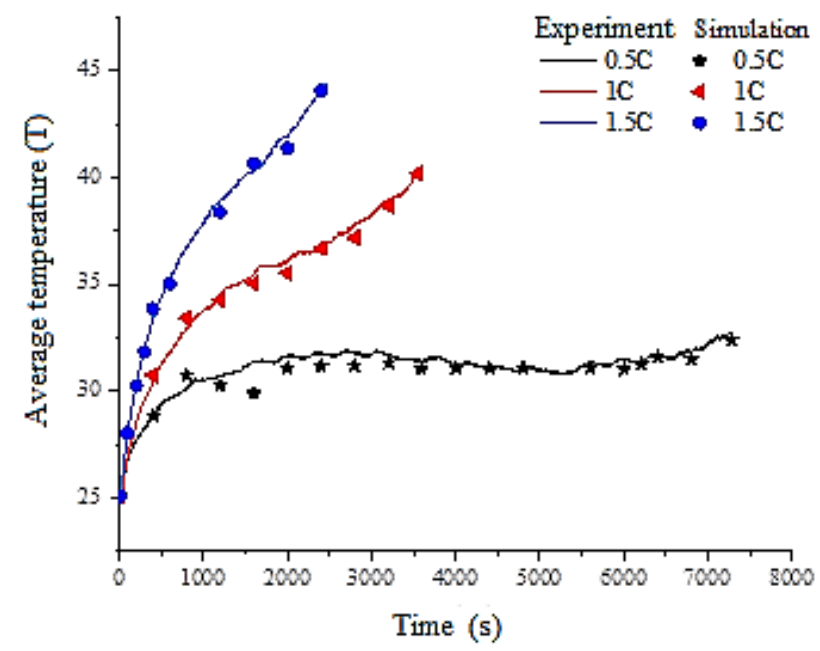

Figure 5. Simulated and measured battery temperature as a function of time, at an ambient temperature of $25^{\circ} \mathrm{C}$

\subsection{Temperature distribution within the battery for the same discharge rates}

The temperature distribution on the battery surface for different ambient temperatures $(15,25$, and $35^{\circ} \mathrm{C}$ ) and different discharge rates are shown in Figure 6. Table 4 shows the temperature values at each test point on the battery surface at the end of the discharge process. Using the temperature distribution map and Table 4, the temperature distribution of the battery was found to be consistent after the discharge had completed. T2 in the positive electrode region of the battery recorded the highest temperature, followed by $\mathrm{T} 1$ in the negative electrode region of the battery. $\mathrm{T} 3$, in the center region of the battery, measured a low temperature, and T4, at the lower edge of the battery surface, showed the lowest temperature.

Table 4. Temperature changes in the different areas of the battery at the end of a discharge $(\mathrm{K})$.

\begin{tabular}{|c|c|c|c|c|c|}
\hline discharge rate & project & $\begin{array}{l}\text { cathode } \\
\text { area } \\
\quad \text { (T1) }\end{array}$ & $\begin{array}{l}\text { positive } \\
\text { area }(\mathrm{T} 2)\end{array}$ & $\begin{array}{l}\text { central area } \\
\text { (T3) }\end{array}$ & $\begin{array}{c}\text { lower } \\
\text { marginal (T4) }\end{array}$ \\
\hline \multirow{3}{*}{$0.5 \mathrm{C}$} & $15^{\circ} \mathrm{C}$ & 297.64 & 297.95 & 297.50 & 297.35 \\
\hline & $25^{\circ} \mathrm{C}$ & 305.92 & 305.21 & 305.84 & 306.70 \\
\hline & $35^{\circ} \mathrm{C}$ & 314.89 & 314.95 & 314.80 & 314.67 \\
\hline \multirow{3}{*}{$1 \mathrm{C}$} & $15^{\circ} \mathrm{C}$ & 304.97 & 305.50 & 304.62 & 304.35 \\
\hline & $25^{\circ} \mathrm{C}$ & 312.47 & 312.61 & 312.08 & 311.91 \\
\hline & $35^{\circ} \mathrm{C}$ & 320.48 & 320.73 & 320.20 & 319.94 \\
\hline \multirow{3}{*}{$1.5 \mathrm{C}$} & $15^{\circ} \mathrm{C}$ & 310.25 & 311.40 & 310.01 & 309.75 \\
\hline & $25^{\circ} \mathrm{C}$ & 316.76 & 316.97 & 316.48 & 316.02 \\
\hline & $35^{\circ} \mathrm{C}$ & 325.79 & 325.91 & 325.00 & 324.75 \\
\hline
\end{tabular}


$\square$

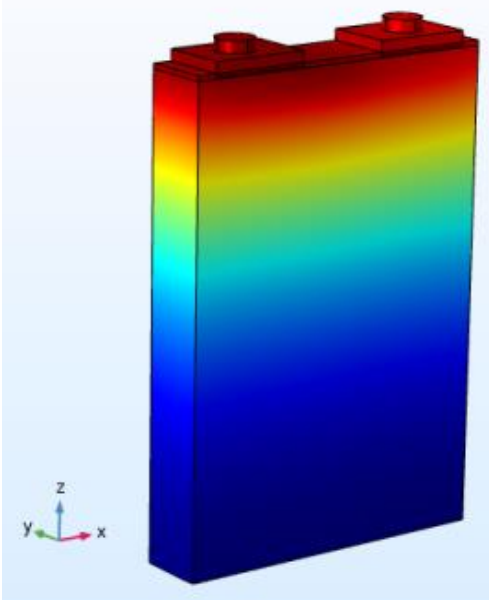

a) Distribution of the surface temperature at $150 \mathrm{C}$ and $0.5 \mathrm{C}$

a

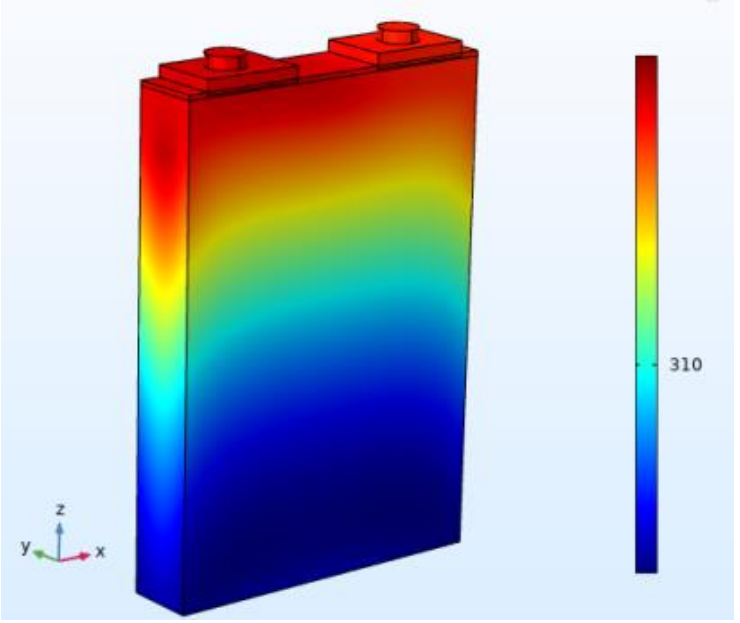

c) Distribution of the surface temperature at $15^{\circ} \mathrm{C}$ and $1.5 \mathrm{C}$

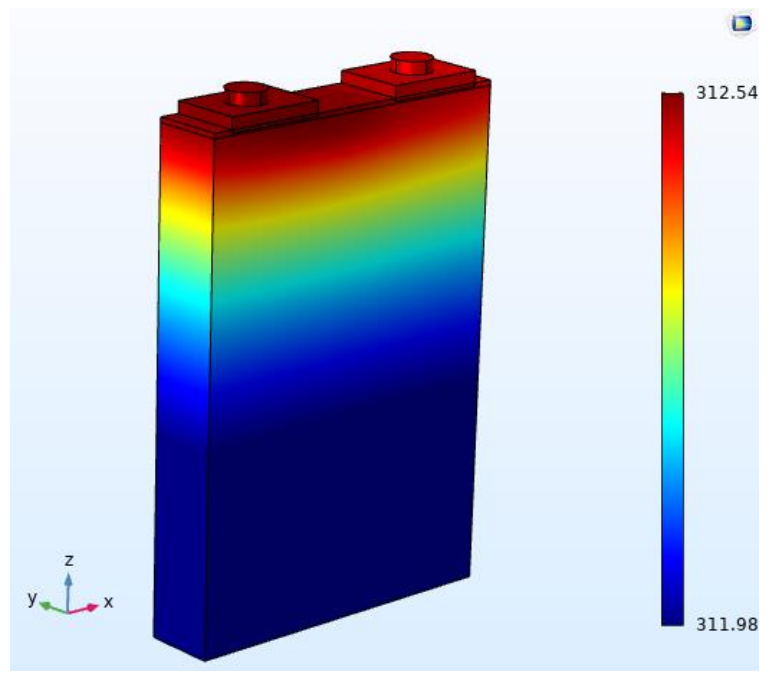

e) Distribution of the surface temperature at $25{ }^{\circ} \mathrm{C}$ and $1 \mathrm{C}$

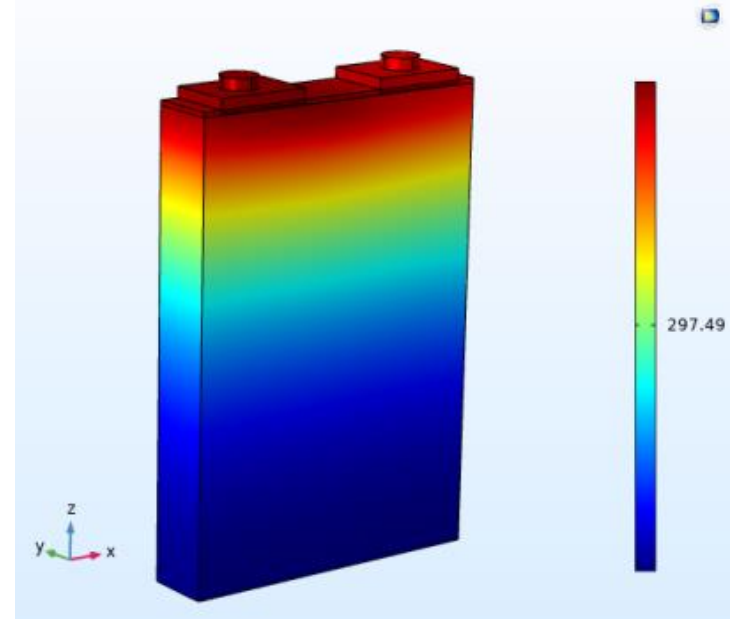

b) Distribution of the surface temperature at $150 \mathrm{C}$ and $1 \mathrm{C}$

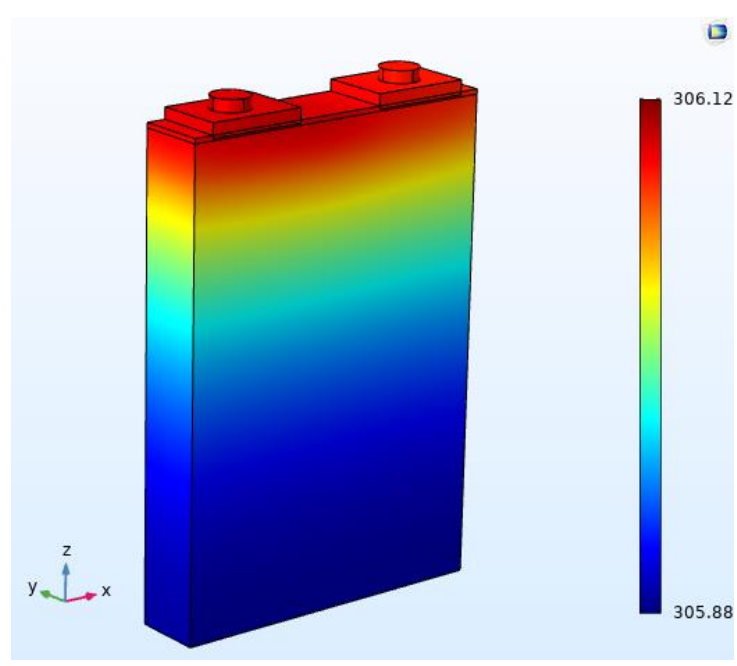

d) Distribution of the surface temperature at $25{ }^{\circ} \mathrm{C}$ and $0.5 \mathrm{C}$

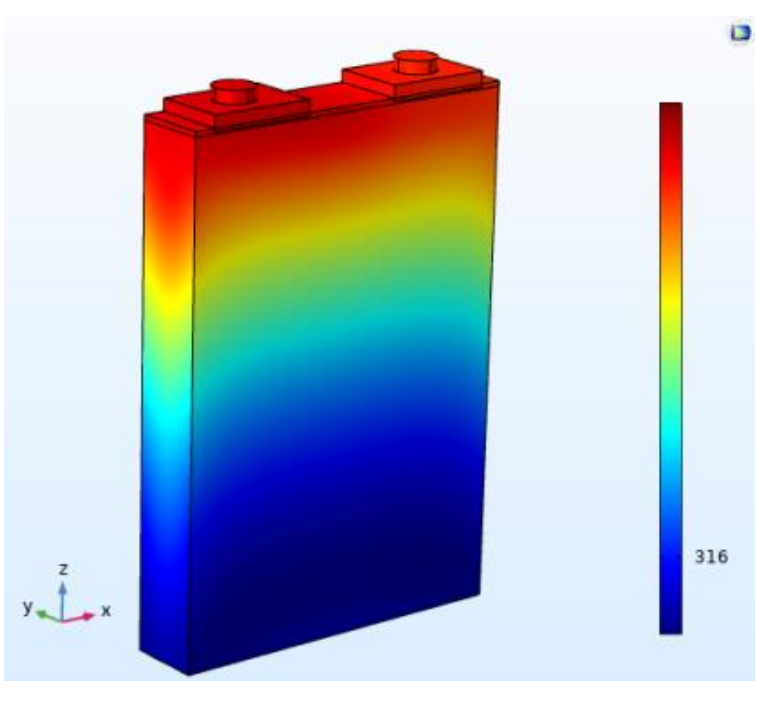

f) Distribution of the surface temperature at $25^{\circ} \mathrm{C}$ and $1.5 \mathrm{C}$ 


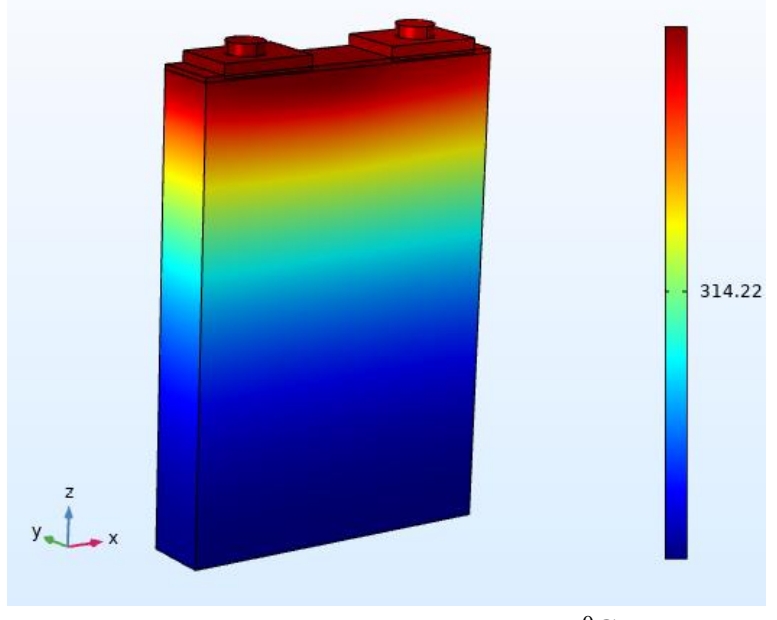

g) Distribution of the surface temperature at $35^{\circ} \mathrm{C}$ and $0.5 \mathrm{C}$

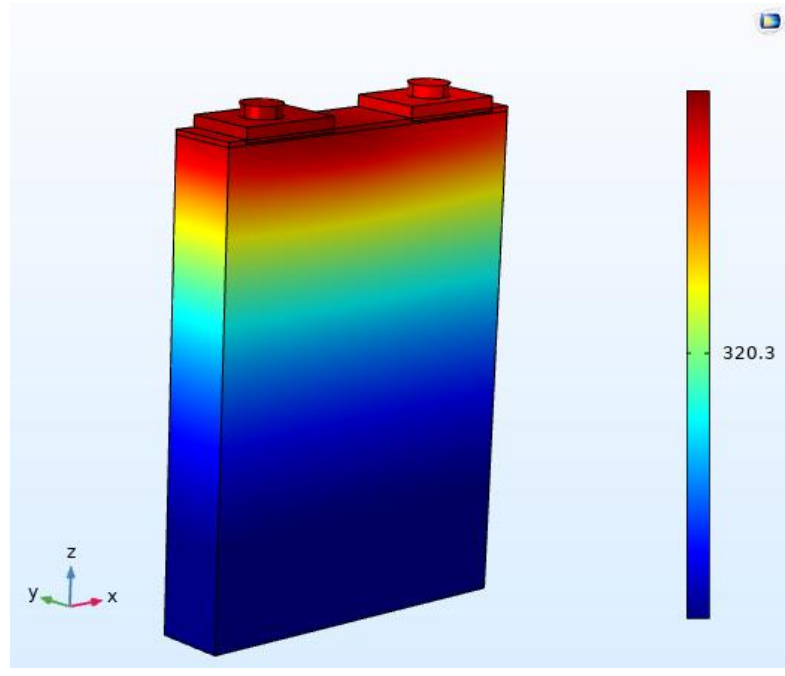

h) Distribution of the surface temperature at $35{ }^{\circ} \mathrm{C}$ and $1 \mathrm{C}$

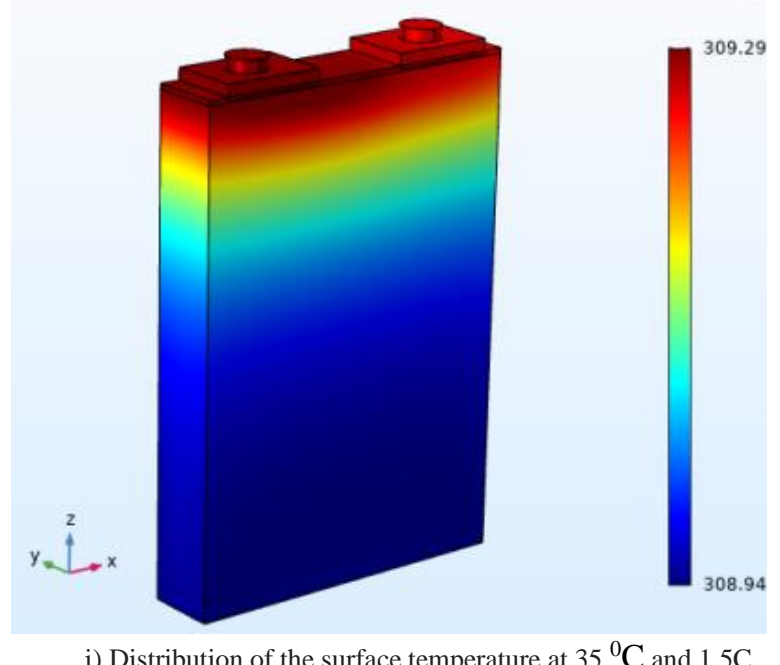

Figure 6. Distribution of the battery surface temperature for different ambient temperatures and discharge rates. $0.5 \mathrm{C}$ represents idle speed [19], $1 \mathrm{C}$ represents uniform speed [20], 1.5C represents acceleration [21]

The observed temperature distribution characteristics could be caused by the following three factors:

a. The electrode conductivities were different (materials), which results in different temperatures for the positive and negative electrodes. Because the electronic conductivity of the active material (lithium iron phosphate) for the anode was lower than the cathode (graphite), the positive electrode transport resistance was higher than for the negative electrode. As a result, the higher internal resistance caused an increase in the polarization heat, thereby increasing the temperature at the positive electrode.

b. A different electrolyte concentration between anode and cathode electrode produced a different current density between the two electrodes, which led to a different temperature distribution for the positive and negative regions. When the battery discharged, the lithium ions detached from the cathode and transferred through the diaphragm to the anode, and the transfer rate of lithium ions in the electrolyte was lower than the rate of intercalation and de-intercalation. Furthermore, the lithium ion concentration in the electrolyte at the cathode increased, while the lithium ions concentration in the electrolyte at the anode decreased. Finally, the lithium ion concentration in the electrolyte at the 
cathode was higher than for the anode during the discharge. This increased the electrochemical reaction heat, ohmic heat, and polarization heat at the anode (e.g. $25{ }^{0} \mathrm{C}, 1.5 \mathrm{C}$ discharge) - Figure 7. The directional movement of lithium ions and the current density in the battery can explain the variation of the battery surface temperature during discharge. This explanation is consistent with the literature [22].

c. The positive and negative electrode fluid collection materials were, respectively, aluminum foil and copper foil. This is the case because the thermal conductivity of copper is higher than the thermal conductivity of aluminum. However, this also further accelerated the negative electrode heatdissipation speed, which results in a higher temperature in the positive area compared to the negative area.

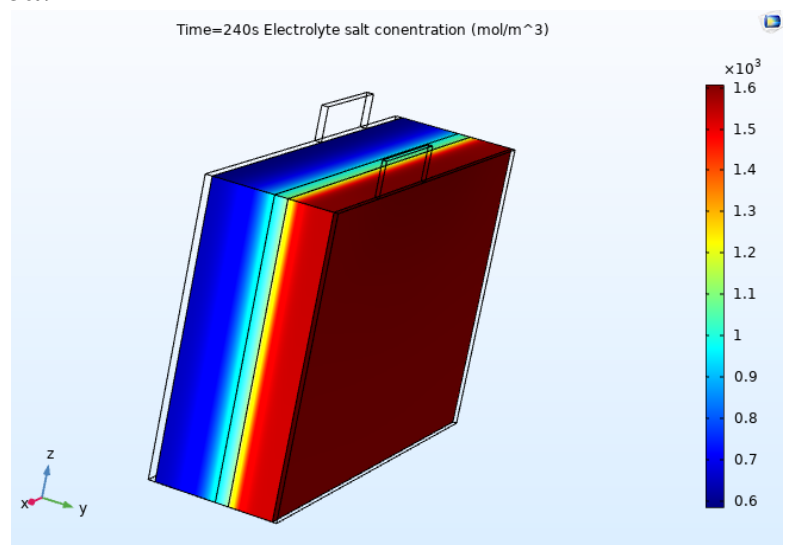

a) Distribution of the electrolyte $\mathrm{Li}$ concentration at $240 \mathrm{~s}$ Time $=1200$ s Electrolyte salt conentration $\left(\mathrm{mol} / \mathrm{m}^{\wedge} 3\right)$

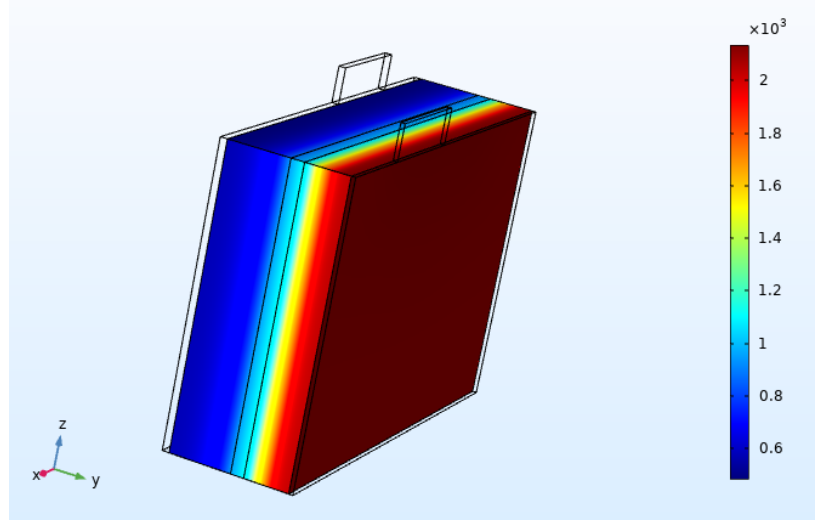

c) Distribution of the electrolyte Li concentration at $1200 \mathrm{~s}$ Time $=2400$ s Electrolyte salt conentration $\left(\mathrm{mol} / \mathrm{m}^{\wedge} 3\right)$

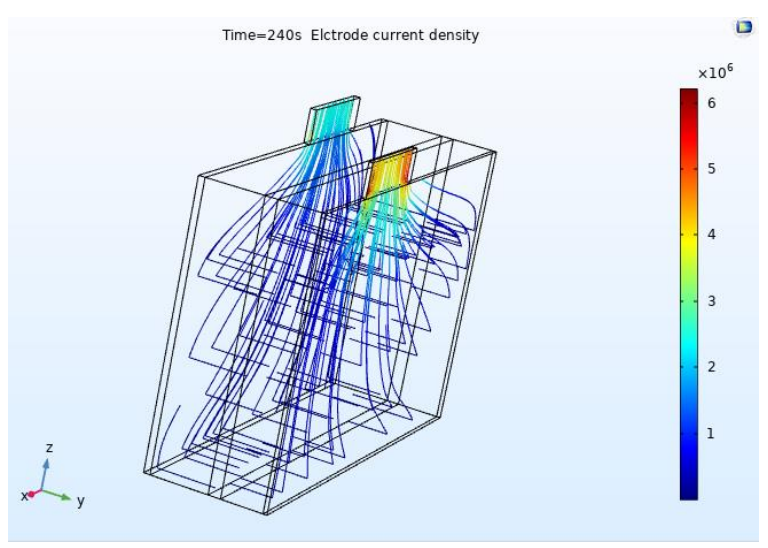

b) Distribution of the electrode current density at $240 \mathrm{~s}$

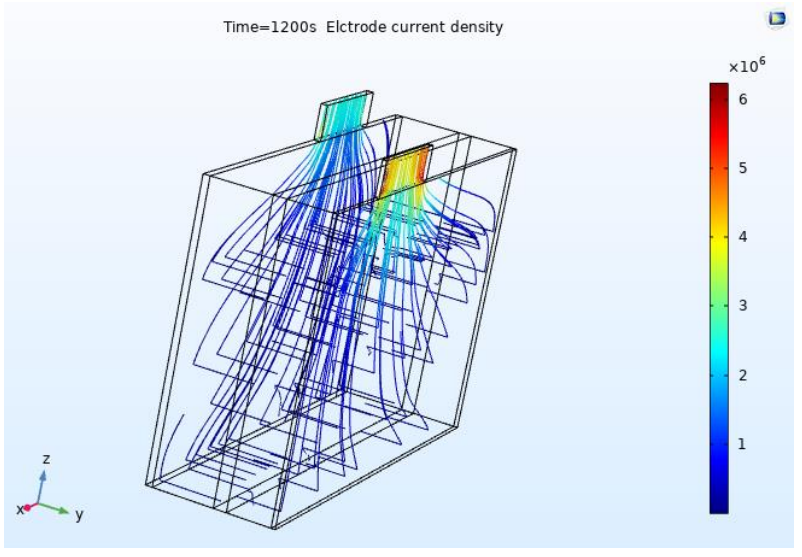

d) Distribution of the electrode current density at $1200 \mathrm{~s}$

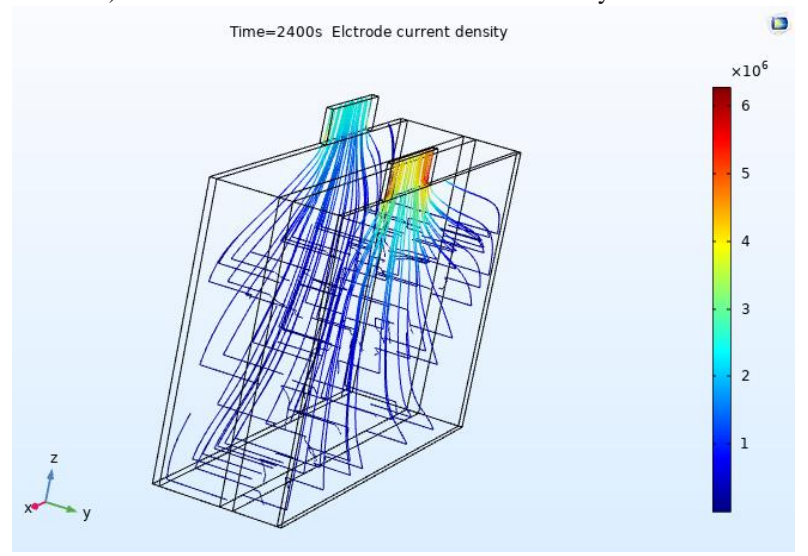

f) Distribution of the electrode current density at $2400 \mathrm{~s}$

e) Distribution of the electrolyte Li concentration at $2400 \mathrm{~s}$

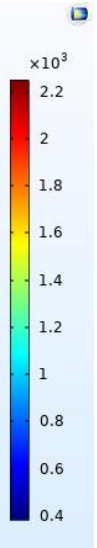

.

Figure 7. Distribution of the lithium ion concentration and current density at different time periods and a discharge of $1.5 \mathrm{C}$ at $25{ }^{\circ} \mathrm{C}$ 


\subsection{Characteristics of the temperature increase at different discharge rates}

The temperature increase for different ambient temperatures $\left(15^{\circ} \mathrm{C}, 25^{\circ} \mathrm{C}\right.$, and $\left.35^{\circ} \mathrm{C}\right)$ and different discharge rates $(0.5 \mathrm{C}, 1 \mathrm{C}$ and $1.5 \mathrm{C})$ is shown in Figure 8. At ambient temperatures of 15, 25, and $35{ }^{\circ} \mathrm{C}$, after discharging at $0.5 \mathrm{C}$, the maximum surface temperatures were $25.62,32.84$, and 43.35 ${ }^{0} \mathrm{C}$ respectively. In addition, the temperature increased by $10.62,7.84$, and $8.35{ }^{\circ} \mathrm{C}$, respectively. When the discharge was completed at $1 \mathrm{C}$, the maximum battery temperatures were $34.30{ }^{\circ} \mathrm{C}, 40.52{ }^{\circ} \mathrm{C}$, and $49.74^{\circ} \mathrm{C}$, respectively, and the temperature increased by $19.3,15.52$, and $14.74{ }^{\circ} \mathrm{C}$, respectively. At the end of the $1.5 \mathrm{C}$ discharge period, the maximum temperatures of the battery were $37.16,44.46$ and $51.55{ }^{\circ} \mathrm{C}$, respectively, and the temperature increased by $22.16,19.46$, and $16.55{ }^{\circ} \mathrm{C}$, respectively. The following can be summarized from Figure 8:

a. In a low-temperature environment $\left(15^{0} \mathrm{C}\right)$ with $0.5 \mathrm{C}$ discharge, the maximum surface temperature of the lithium ion battery was $25.62{ }^{\circ} \mathrm{C}$, and the temperature increased by $10.62^{\circ} \mathrm{C}$. In a high-temperature environment $\left(35^{\circ} \mathrm{C}\right)$, the maximum surface temperature of the battery was $43.35{ }^{0} \mathrm{C}$, and the temperature increased by $8.35{ }^{\circ} \mathrm{C}$. Compared with $15{ }^{\circ} \mathrm{C}$, the temperature increase occurred more slowly. The temperature increase decreases with increasing ambient temperature for the same discharge rate.

b. From the overall trend of Figure 8, it can be concluded that the temperature of the lithium battery increased with increasing discharge ratio for a given ambient temperature.

c. It can also be seen that, for different discharge ratios $(0.5 \mathrm{C}, 1 \mathrm{C}$ and $1.5 \mathrm{C})$, the battery surface temperature increased significantly in two stages: The first stage was the initial discharge stage, while the second stage represented the end of the discharge period, when the battery surface temperature tended to increase slowly.

d. It can be concluded that the maximum surface temperature was above $40^{\circ} \mathrm{C}$ for ambient temperatures of 25 and $35^{\circ} \mathrm{C}$, which exceeded the optimal operating temperature range of the battery. Therefore, effective heat dissipation of the battery is required for these conditions.

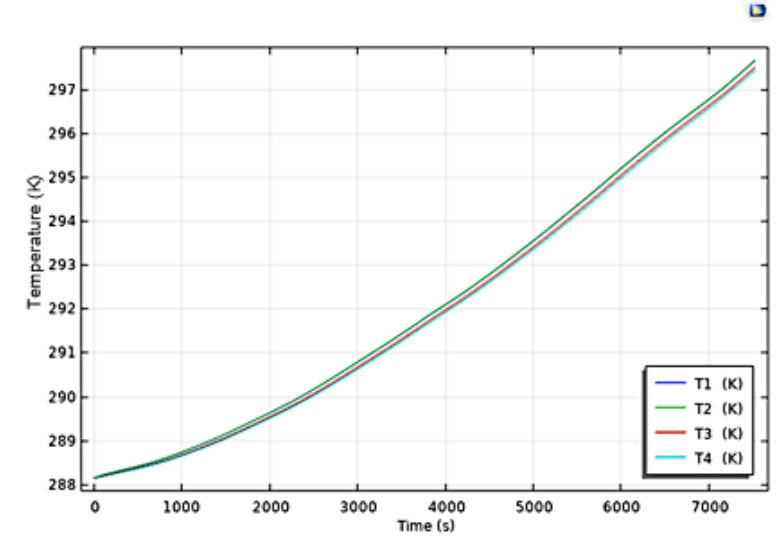

a) Temperature vs. time at $15{ }^{\circ} \mathrm{C}$ and $0.5 \mathrm{C}$

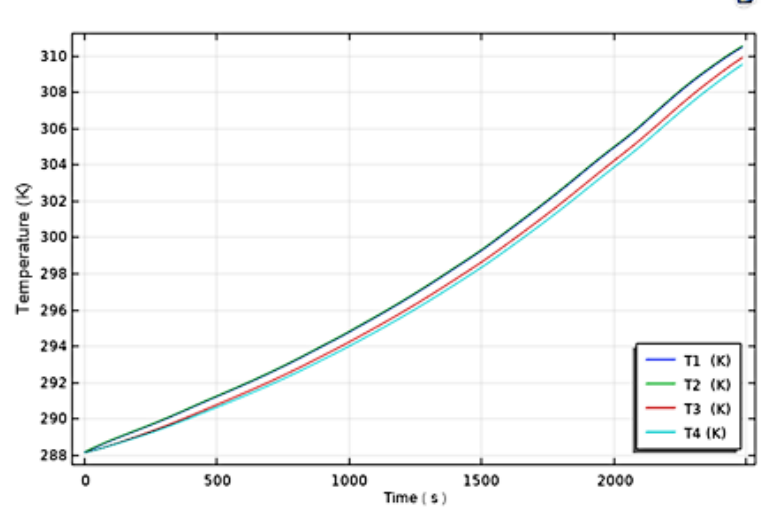

c) Temperature vs. time at $15^{\circ} \mathrm{C}$ and $1.5 \mathrm{C}$

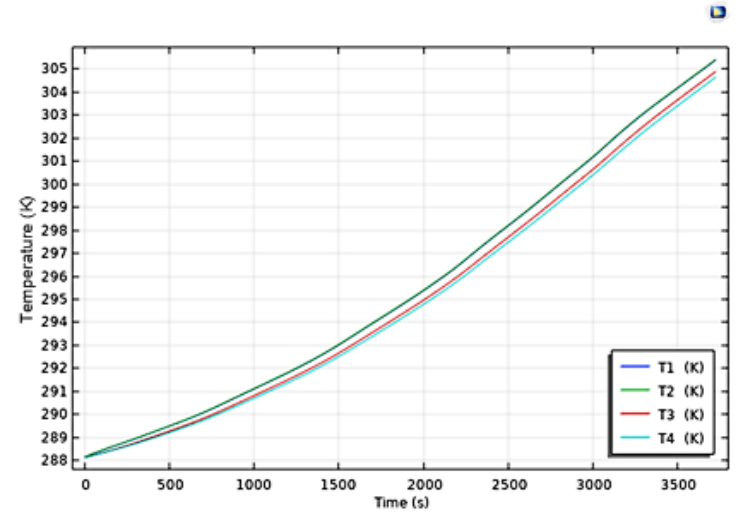

b) Temperature vs. time at $15{ }^{\circ} \mathrm{C}$ and $1 \mathrm{C}$

○

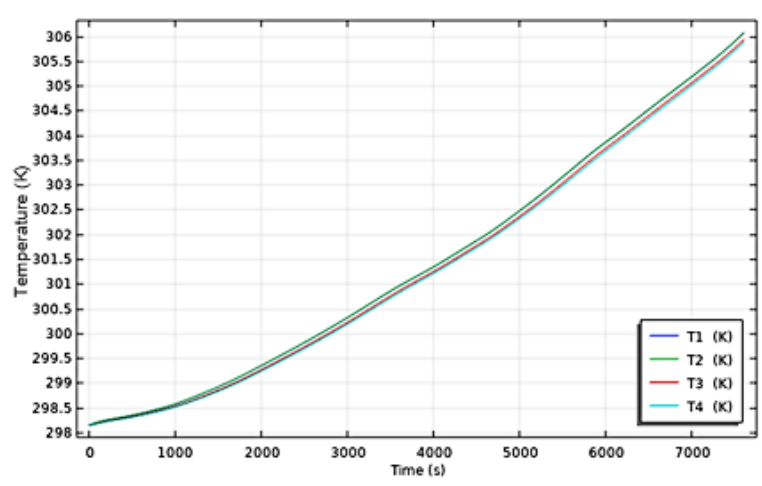

d) Temperature vs. time at $25{ }^{\circ} \mathrm{C}$ and $0.5 \mathrm{C}$ 
○

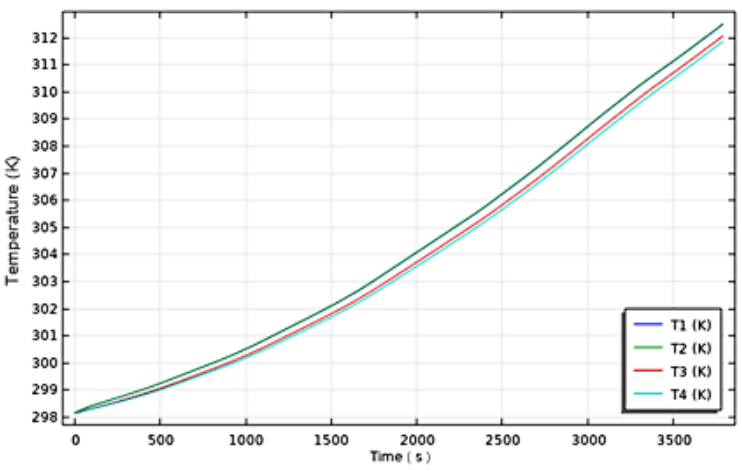

e) Temperature vs. time at $25{ }^{\circ} \mathrm{C}$ and $1 \mathrm{C}$

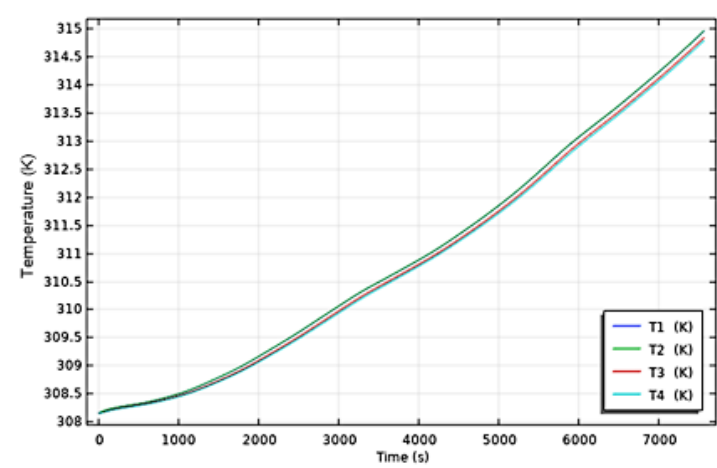

g) Temperature vs. time at $350 \mathrm{C}$ and $0.5 \mathrm{C}$

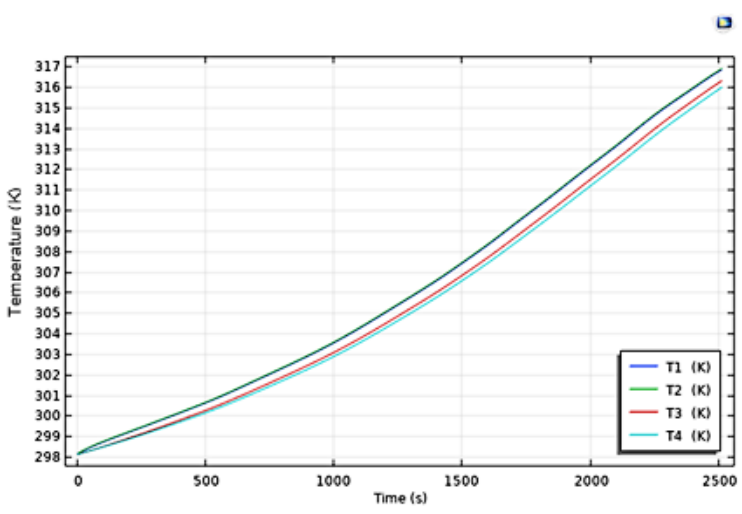

f) Temperature vs. time at $25{ }^{\circ} \mathrm{C}$ and $1.5 \mathrm{C}$

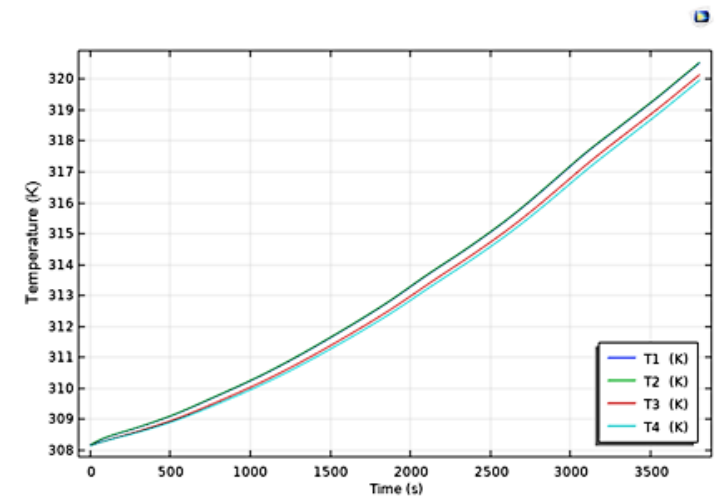

h) Temperature vs. time at $350 \mathrm{C}$ and $1 \mathrm{C}$

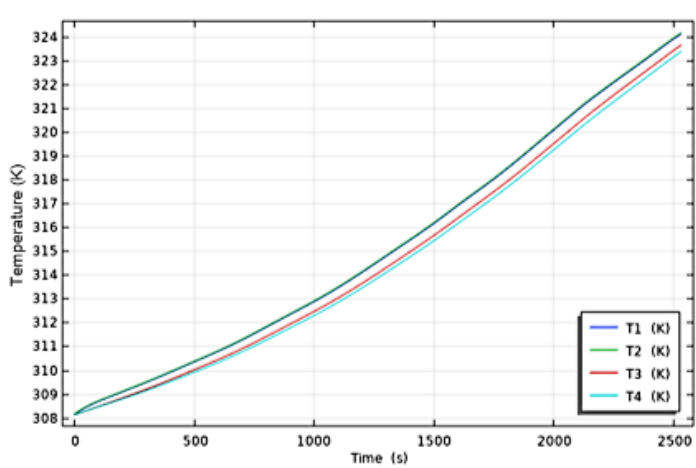

i) Temperature vs. time at $35{ }^{\circ} \mathrm{C}$ and $1.5 \mathrm{C}$

Figure 8. The battery's surface temperature as a function of time for different ambient temperatures and different discharge rates

The temperature variation of the lithium battery monomer at different ambient temperatures and different discharge rates can be explained using the heat generation properties of the battery during discharge, considering the following points:

a. At low temperature $\left(15^{\circ} \mathrm{C}\right)$, the chemical reaction that takes place inside the battery slows down, the diffusion of lithium ions slows, the mobility decreases, the solubility of lithium electrolytic salts in organic solvents decreases, the viscosity of organic solvents increases, and the conductivity of electrolyte was low. The overall effect ultimately increases the internal resistance, which produced more irreversible heat, and increases the heat output quickly. This resulted in larger temperature changes. With increasing temperature, the diffusion rate of the lithium ion increased, the conductivity of the electrolyte increased, the internal resistance decreased, and, thus, the irreversible thermal reaction rate was reduced. Therefore, the total heat increased slowly and the temperature increase was slow too. 
b. The total output of heat from the battery consisted of reversible heat (reaction heat) and irreversible heat (ohmic heat and polarization heat). The reversible heat was proportional (positively) to the current, while the irreversible heat was proportional to the fourth power of current. Therefore, at low current discharge $(0.5 \mathrm{C})$, the total heat of the battery consisted mainly of reversible heat, and some irreversible heat. In other words, the total heat increase was small, and the temperature of the battery increased only slowly. For discharging at higher currents $(>1 \mathrm{C})$, the increase in irreversible heat was faster than for reversible heat, and the irreversible heat was the main component of the total heat. This has been explained previously [23-25] based on an internal battery-resistance increases that occurs sharply near the end of the discharge period. Hence, the total heat increased significantly and the temperature increase was rapid. This can be seen from the reversible and irreversible heat curves in Figure 9 , e.g. for $0.5 \mathrm{C}, 1 \mathrm{C}, 1.5 \mathrm{C}$ at $25^{\circ} \mathrm{C}$. In other words, with gradually increasing discharge ratio, the surface temperature of the single battery followed overall a warming trend.

In addition, the obvious increase of battery surface temperature mostly occurred in two stages: the initial stage of discharge, and the end stage of discharge. During the discharge process, the rise in the battery surface temperature increased slowly. The reasons for this can be summarized as follows:

During the whole discharge process, reversible heat was exothermic in the early discharge stage. Then, it gradually became endothermic, and finally, exothermic. Irreversible heat was exothermic during the whole discharge process. Before the end of the discharge process, it tended to stabilize, and increased with increasing discharge ratios. Especially, after the discharge had completed, it did increase rapidly, which was led by a significant increase of the internal resistance of the battery. Based on the previous discussion, the total heat of the battery increased rapidly at both the beginning and end of the discharge, and the surface temperature of the battery increased substantially. During discharge, the total heat of the battery increased slowly and the surface temperature of the battery increased slowly too [25-36].

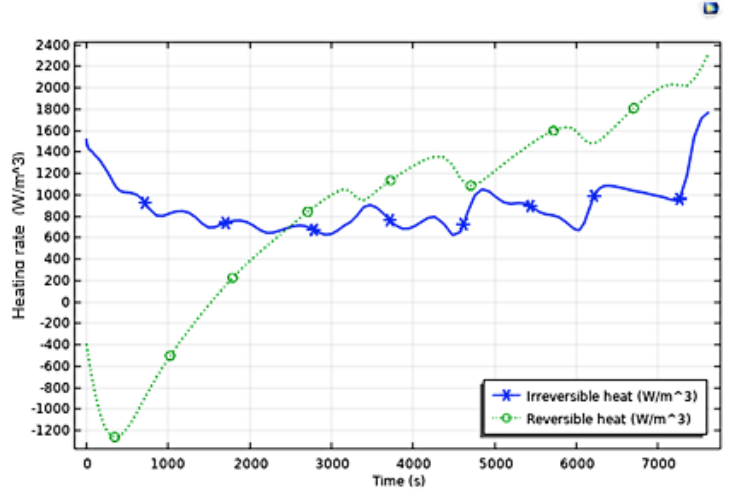

a) Reversible and irreversible heat vs. time at $0.5 \mathrm{C}$

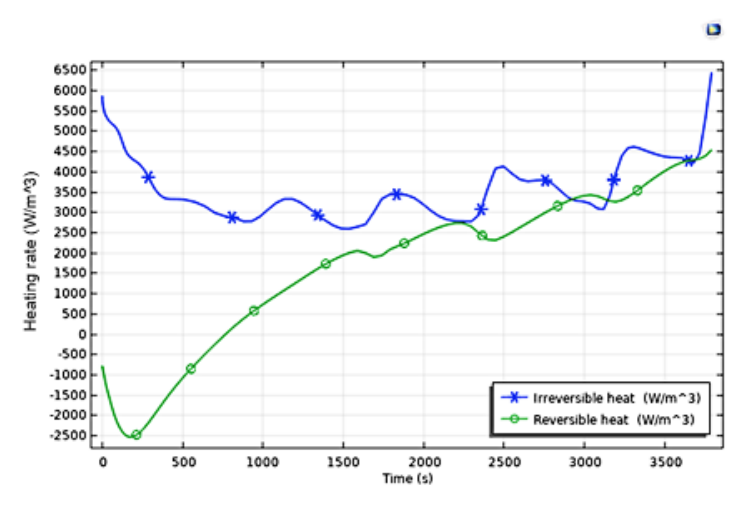

b) Reversible and irreversible heat vs. time at 1C

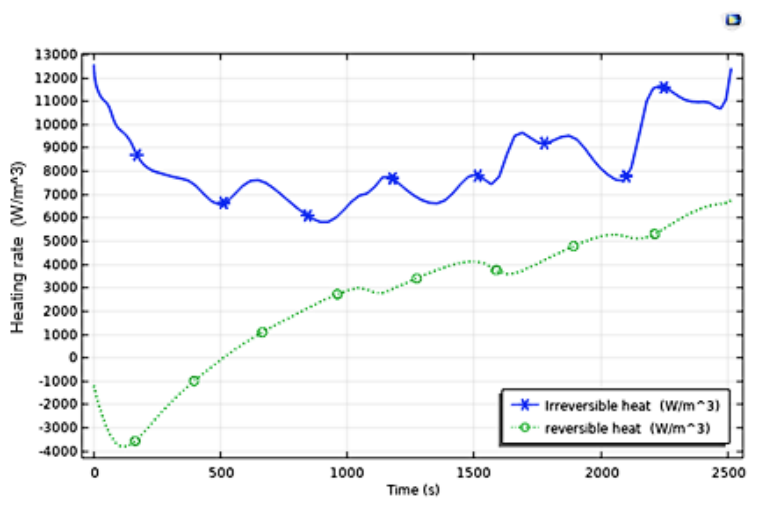

c) Reversible and irreversible heat vs. time at $1.5 \mathrm{C}$

Figure 9. Reversible heat and irreversible heat as a function of time, at different discharge rates at $25^{\circ} \mathrm{C}$ 


\section{Conclusions}

Using the coupling of mass, charge, and energy conservation, as well as principles of electrochemistry and kinetics, a three-dimensional electrochemical/thermal model was developed for a commercial 68Ah lithium iron phosphate battery, and the thermal characteristics of the lithium battery was analyzed. The following conclusions were drawn:

(1) The finite element method was used to develop a three-dimensional electrochemical/thermal model for a lithium battery, using COMSOL simulation software. After a comparison and analysis of the simulation and experimental results, we were able to confirm that this electrochemical/thermal model could indeed accurately describe the thermal characteristics of a lithium battery, under various working conditions.

(2) The electrochemical/thermal model was used to study and analyze the thermal characteristics of a monomer battery in different environments $\left(15,25\right.$, and $\left.35^{\circ} \mathrm{C}\right)$. The results indicate that the temperature increase of the lithium battery increased with increasing discharge ratio, and a rapid temperature increase was observed for higher discharge-ratios.

Furthermore, the three-dimensional electrochemical/thermal model was used to study and analyze the thermal characteristics of a monomer battery and different discharge rates $(0.5 \mathrm{C}, 1 \mathrm{C}, 1.5 \mathrm{C})$. The results show that the temperature increase in the lithium battery occurs mainly near the anode and cathode while a lower temperature was observed in lower area near the bottom edge.

(3) The electrochemical/thermal model of the monomer lithium battery was able to explain and help analyze the thermal properties of a lithium battery accurately in terms of both heat generation and heat transfer.

Acknowledgments: Support of this work by the Fundamental Research Funds for the Central Universities (Grant No.2572018GB03) is gratefully acknowledged.

\section{References}

1. TERATANI, T., MIZUTANI, R., YAMAMOTO, K., ANEGAWA, T., Energy-saving technologies for automobiles,.IEEJ Trans. Electr. Electron. Eng., 3, 2008, 162-175.

2. LI, J., WANG, D., PECHT, M., An electrochemical model for high C-rate conditions in lithiumion batteries. J. Power Sources, 435, 2019, 226885.

3. LI, J., CHENG, Y., AI, L., JIA, M., DU, S., YIN, B., WOO, S., ZHANG, H., 3D simulation on the internal distributed properties of lithium-ion battery with planar tabbed configuration. J. Power Sources, 293, 2015, 993-1005.

4. GU, F., GUO, J., YAO, X., SUMMERS, P. A., WIDIJATMOKO, S. D., HALL, P., An investigation of the current status of recycling spent lithium-ion batteries from consumer electronics in China. J. Clean. Prod., 161, 2017, 765-780.

5. PATIL, R. S., JUVEKAR, V. A., Analysis of multiparticle bipolar electrolysis using single particle cell model. Chem. Eng. Sci., 110, 2014, 72-82.

6. HU, X., LI, S., PENG, H., A comparative study of equivalent circuit models for Li-ion batteries. $J$. Power. Sources., 198, 2012, 359-367.

7. SAW, L. H., YE, Y., TAY, A. A. O., Electro-thermal characterization of lithium iron phosphate cell with equivalent circuit modeling. Energy. Convers. Manage., 87, 2014, 367-377.

8. RAMADESIGAN, V., NORTHROP, P. W., DE, S., SANTHANAGOPALAN, S., BRAATZ, R. D., SUBRAMANIAN, V. R., Modeling and simulation of lithium-ion batteries from asystems engineering perspective. J. Electrochem. Soc., 159, 2012, R31-R45.

9. JAGUEMONT, J., BOULON, L., DUBÉ, Y., A comprehensive review of lithium-ion batteries used in hybrid and electric vehicles at cold temperatures. Appl. Energy., 164, 2016, 99-114.

10. FOTOUHI, A., AUGER, D. J., PROPP, K., LONGO, S., WILD, M., A review on electric vehicle battery modelling: from lithium-ion toward lithium-sulphur. Renew. Sustain. Energy. Rev., 56, 2016, 1008-1021. 
11. WANG, Q., JIANG, B., LI, B., YAN, Y., A critical review of thermal management models and solutions of lithium-ion batteries for the development of pure electric vehicles. Renew. Sustain. Energy Rev., 64, 2016, 106-128.

12. ZHAO, R., ZHANG, S., LIU, J., GU, J., A review of thermal performance improving methods of lithium ion battery: electrode modification and thermal management system. J. Power. Sources., 299, 2015, 557-577.

13. IANG, J., RUAN, H., SUN, B., ZHANG, W., GAO, W., ZHANG, L., A reduced lowtemperature electro-thermal coupled model for lithium-ion batteries. Appl. Energy, 177 (2016) 804-816.

14. XU, M., ZHANG, Z., WANG, X., JIA, L., YANG, L., A pseudo three-dimensional electrochemical-thermal model of a prismatic LiFePO4 battery during discharge process. Energ., 80, 2015, 303-317.

15. NILESHWAR, P.R., MCGORDON, A., ASHWIN, T.R., GREENWOOD, D., Parametric Optimization Study of a Lithium-ion Cell. Energy Procedia, 138, 2017, 829-834.

16. FANG, W., KWON, O. J., WANG, C. Y., Electrochemical-thermal modeling of automotive Li-ion batteries and experimental validation using a threeelectrode cell. Int. J. Energ. Res., 34, 2010, 107115.

17. CAO, Y., WANG, Q., FAN, Q., NOJAVAN, S., JERMSITTIPARSERT, K., Risk-constrained stochastic power procurement of storage-based large electricity consumer. J. Energ. Stor., 28, 2020, 101183.

18. GHALKHANIA, M., BAHIRAEIB, F., NAZRIC, G.A., SAIFA, M., Electrochemical-Thermal Model of Pouch-type Lithium-ion Batteries. J. Electrochim. Acta, 247, 2017, 569-587.

19. WU, M.S., LIU, K.H., WANG, Y.Y., WAN, C.C., Heat dissipation design for lithium-ion batteries, J. Power Sources, 109, 2002, 160-166.

20. KHATEEB, S.A., AMIRUDDIN, S., FARID, M., SELMAN, J.R., AL-HALlAJ, S., Thermal management of Li-ion battery with phase change material for electric scooters: experimental validation, J. Power Sources, 142, 2005, 345-353.

21. LIU, R., CHEN, J., XUN, J., JIAO, K., DU, Q., Numerical investigation of thermal behaviors in lithium-ion battery stack discharge, Appl. Energ., 132, 2014, 288-297.

22. ZHANG, T., WU, X., SHAHEEN, S. M., ZHAO, Q., LIU, X., RINKLEBE, J., REN, H., Ammonium nitrogen recovery from digestate by hydrothermal pretreatment followed by activated hydrochar sorption. Chem. Eng. J., 379, 2020, 122254.

23. BANDHAUER, T.M., GARIMELLA, S., FULLER, T.F., A critical review of thermal issues in lithium-ion batteries. J. Electrochem. Soc., 158, 2011, R1-R25.

24. JAGUEMONT, J., BOULON, L., DUBÉ, Y., A comprehensive review of lithium-ion batteries used in hybrid and electric vehicles at cold temperatures. Appl. Energy, 164, 2016, 99-114.

25. WANG, P., LI, J. B., BAI, F. W., LIU, D. Y., XU, C., ZHAO, L., WANG, Z. F., Experimental and theoretical evaluation on the thermal performance of a windowed volumetric solar receiver. Energy, 119, 2017, 652-661.

26. LIU, Z., FENG, J., WANG, J., Resource-Constrained Innovation Method for Sustainability: Application of Morphological Analysis and TRIZ Inventive Principles. Sustainability, 12(3), 2020, 917-939.

27. GU, F., GUO, J., ZHANG, W., SUMMERS, P. A., HALL, P., From waste plastics to industrial raw materials: A life cycle assessment of mechanical plastic recycling practice based on a real-world case study. Sci. Total. Environ., 601, 2017, 1192-1207.

28. HAIBIN, L. ZHENLING, L., Recycling utilization patterns of coal mining waste in China. Resour. Conserv. Recycle., 54(12), 2010, 1331-1340.

29. WANG, H., WANG, J., LU, H., BO, G., ZHANG, X., CAO, Y., LIU, L., ZHANG, J., ZHANG, W., Analysis of coating electrode characteristics in the process of removing pollutants from wastewater. Fresenius. Environ. Bull., 29(2), 2020, 715-721.

30. CHENG, Y., SONG, Z., JIN, J., WANG, J., WANG, T., Experimental study on stress wave 
attenuation and energy dissipation of sandstone under full deformation condition. Arab. J. Geosci., 12(23), 2019, 736-749.

31. CHEN, H., FAN, D., HUANG, J., HUANG, W., ZHANG, G., HUANG, L., Finite Element Analysis Model on Ultrasonic Phased Array Technique for Material Defect Time of Flight Diffraction Detection. Sci. Adv. Mater., 12(5), 2020, 665-675.

32. ZENG, L., CHEN, G., CHEN, H., Comparative Study on Flow-Accelerated Corrosion and Erosion-Corrosion at a $90^{\circ}$ Carbon Steel Bend. Materials, 13(7), 2020, 1780-1795.

33. LIU, Z., FENG, J., WANG, J., Effects of the sharing economy on sequential innovation products. Complexity, 2019, 1-18.

34. ZHAO, N., XIA, M., MI, W., Modeling and solution for inbound container storage assignment problem in dual cycling mode. Discrete. Cont. Dyn. Sys., 2018, 1-13.

35. ZENG, H. B., LIU, X. G., WANG, W., A generalized free-matrix-based integral inequality for stability analysis of time-varying delay systems. App. Math. Comput., 354, 2019, 1-8.

36. GUO, J., PAN, J., GUO, J., GU, F., KUUSISTO, J., Measurement framework for assessing disruptive innovations. Technol. Forecast. Soc. Change., 139, 2019, 250-265.

Manuscript received: 17.03 .2020 